\title{
Impact of COVID-19 infection on life expectancy, premature mortality, and DALY in Maharashtra, India
}

\author{
Guru Vasishtha ${ }^{1 *}$ (D, Sanjay K. Mohanty ${ }^{2}$, Udaya S. Mishra ${ }^{3}$, Manisha Dubey ${ }^{4}$ and Umakanta Sahoo'
}

\begin{abstract}
Background: The COVID-19 infections and deaths have largely been uneven within and between countries. With $17 \%$ of the world's population, India has so far had 13\% of global COVID-19 infections and 8.5\% of deaths. Maharashtra accounting for $9 \%$ of India's population, is the worst affected state, with 19\% of infections and 33\% of total deaths in the country until 23rd December 2020. Though a number of studies have examined the vulnerability to and spread of COVID-19 and its effect on mortality, no attempt has been made to understand its impact on mortality in the states of India.
\end{abstract}

Method: Using data from multiple sources and under the assumption that COVID-19 deaths are additional deaths in the population, this paper examined the impact of the disease on premature mortality, loss of life expectancy, years of potential life lost (YPLL), and disability-adjusted life years (DALY) in Maharashtra. Descriptive statistics, a set of abridged life tables, YPLL, and DALY were used in the analysis. Estimates of mortality indices were compared preand during COVID-19.

Result: COVID-19 attributable deaths account for $5.3 \%$ of total deaths in the state and have reduced the life expectancy at birth by 0.8 years, from 73.2 years in the pre-COVID-19 period to 72.4 years by the end of 2020. If COVID-19 attributable deaths increase to $10 \%$ of total deaths, life expectancy at birth will likely reduce by 1.4 years. The probability of death in $20-$ 64 years of age (the prime working-age group) has increased from 0.15 to 0.16 due to COVID-19. There has been 1.06 million additional loss of years (YPLL) in the state, and DALY due to COVID-19 has been estimated to be 6 per thousand.

Conclusion: COVID-19 has increased premature mortality, YPLL, and DALY and has reduced life expectancy at every age in Maharashtra.

Keywords: COVID-19, Premature mortality, Life expectancy, YPLL, DALY, Maharashtra

\section{Introduction}

In a short span of 1 year, COVID-19 has emerged as the largest-ever health crisis of the twenty-first century. With over 78 million infections and 1.7 million deaths attributable to it until 23rd December 2020, COVID-19 attributable deaths account for $2.9 \%$ of additional deaths

\footnotetext{
*Correspondence: guruvasishth15@gmail.com

${ }^{1}$ International Institute for Population Sciences, Govandi Station Road, Deonar, Mumbai, Maharashtra 400088, India

Full list of author information is available at the end of the article
}

worldwide $[1,2]$. The global spread of COVID-19 infection and attributable mortality has been highly uneven among and within countries. With 18.6 million infections and 3,30,824 COVID-19 attributable deaths, the USA accounts for $23.8 \%$ of global infections and 19.2\% of global deaths [1]. India, with over 10 million infected cases and 1,46,476 COVID-19 deaths, is the secondlargest country with respect to the size of infection and is ranked third with respect to COVID-19 attributable deaths [1]. The actual number of infections in many

(c) The Author(s). 2021 Open Access This article is licensed under a Creative Commons Attribution 4.0 International License, which permits use, sharing, adaptation, distribution and reproduction in any medium or format, as long as you give appropriate credit to the original author(s) and the source, provide a link to the Creative Commons licence, and indicate if changes were made. The images or other third party material in this article are included in the article's Creative Commons licence, unless indicated otherwise in a credit line to the material. If material is not included in the article's Creative Commons licence and your intended use is not permitted by statutory regulation or exceeds the permitted use, you will need to obtain permission directly from the copyright holder. To view a copy of this licence, visit http://creativecommons.org/licenses/by/4.0/. The Creative Commons Public Domain Dedication waiver (http://creativecommons.org/publicdomain/zero/1.0/) applies to the data made available in this article, unless otherwise stated in a credit line to the data. 
countries, including India, remains underestimated due to the asymptomatic nature of the infection and inadequate testing and surveillance system.

As the COVID-19 infection continues to spread, an increasing number of studies have become available on the extent of infection, the associated risk factors, and the crude fatality ratio (CFR) with and without time lag, projecting deaths and estimating the loss of life expectancy, premature mortality, and YPLL across countries [3-9]. Findings suggest that the infection rate across populations is largely underestimated, while the CFR shows large variations across countries, geographies, and demographic characteristics. The demographic structure, availability of health care resources, and multimorbid conditions explain COVID-19 attributable deaths to a larger extent $[3,10-$ 14]. In China, fever, dyspnea, and chest pain/discomfort have been the more common symptom among the deceased patients, while fever has the most common symptom among the surviving patients $[3,10]$. Older adults, people with comorbidities, and men are more susceptible to COVID-19 fatality [11, 15].

Evidence suggests that people with the COVID-19 infection are more prone to many life-threatening morbidities and fatalities $[11,16]$. A study conducted in Italy found that fatigue, dyspnea, joint pain, and chest pain were persistent among the recovered patients [16]. Studies have projected premature mortality and reduction in life expectancy due to the infection across countries [4, $8,17,18]$. After a certain threshold level of COVID-19 prevalence, life expectancy starts decreasing. In North America, Europe, Latin America, and the Caribbean, life expectancy at birth has been estimated to have reduced by 1 year at $10 \%$ prevalence of infection [4]. The COVID-19 attributable mortality has the potential to reduce life expectancy in India, weekly and annual life expectancy at birth in Spain, and seasonal life expectancy in Italy $[8,17,18]$. Besides mortality, many studies are available on the vulnerability to the COVID-19 infection, and mental distress, and loss of livelihood due to the preventive measures for containing the virus $[19,20]$.

The spread of COVID-19 has been largely uneven across the states of India. With 123 million population (9\% of India's population), Maharashtra is the second most populous and urbanized state in the country. It is one of the more developed states and ranks high on the human development index [21]. However, Maharashtra is the worst affected state with respect to COVID-19 infections and mortality. Until 23rd December 2020, it had 1.9 million cases and 48,876 deaths due to COVID-19, accounting for $19 \%$ of total infections and $34 \%$ of all COVID-19 attributable deaths in the country [22]. The case-fatality ratio in the state is higher than the national average. It has been observed that the rapid community transmission of the virus in a short time has resulted in a higher incidence of the disease and deaths resulting from it and, consequently, has affected the life expectancy [12]. Many states, including Maharashtra, are now experiencing the second and the third waves of the COVID-19 pandemic. With the global literature hinting at the implications of COVID-19 for longevity, it becomes imperative to make a regional assessment of the same owing to the disproportionately high load of infections and deaths due to the pandemic in the region. This assessment involves premature mortality, with its consequential bearing on life expectancy, person-years of life lost, and disability-adjusted life years (DALY). With the age-specific load of the infection and fatalities, personyears of life lost offers an understanding into the skewed share of life lost during the productive years, which has implications not only for a macro assessment, but also for household-level micro assessment. Years of potential life lost (YPLL) is a summary measure of premature mortality that reflects the sum of years lost from a predefined age, such as standard life expectancy. A higher YPLL is indicative of premature mortality and contributes to the compression of life expectancy. DALY measures the disease burden of the population and consists of YPLL and Years Lived with Disability (YLD). DALY serves to understand the implications of differential severity of the disease for individuals conditioned by their age, sex, and any pre-disposed condition. In the context of the COVID-19 pandemic, estimating YPLL and DALY is appropriate as over two-thirds of deaths are under 70 years of age 'a standard age for estimating YPLL' [2]. Patients affected by COVID-19 have long-term health complications and are more likely to be morbid than non-COVID-19 patients [23]. In ultimate terms, the loss of life expectancy in a regional setting reflects the severity of the pandemic with sustained and periodic soaring of infection in the state. In this context, this paper examines the effect of COVID-19 on premature mortality, life expectancy, YPLL, and DALY in one of the worst affected states of India, Maharashtra.

\section{Data and methods}

Data for this paper was drawn from multiple sources. These include the Report of the Expert Committee on Population Projections, Sample Registration System (SRS) Statistical Report 2018, and other published sources. The population size and distribution for Maharashtra for the year 2020 were taken from the Report of the Expert Committee on Population Projections [24]. The age-specific death rates for the state for the year 2018 (latest available data) were taken from the SRS Statistical Report and labelled as death rate without the COVID-19 infection [25]. The COVID-19 confirmed cases and deaths by age group were taken from the Times of India reports, dated 7th December 2020 and 
21st December 2020 [26, 27]. The total number of confirmed cases and deaths until 20th December 2020 for Maharashtra and India were taken from covid19india. org [22]. We redistributed the total deaths until 20th December 2020, as per the distribution of deaths for which age data was available (7th December 2020). Agespecific case fatality ratio (ASCFR) was computed from the given data.

\section{Methods}

Descriptive statistics, abridged life tables, and estimates of YPLL and DALY were used in the analysis. It was assumed that COVID-19 attributable deaths are unprecedented additional deaths that could have been averted in the absence of COVID-19. A set of abridged life tables were generated to estimate life expectancy at various ages, premature mortality, and YPLL and DALY were used in the analysis. The probability of death by age 70 and between age 20 and age 64 was computed and termed as premature mortality. Estimates were classified under the five scenarios. Scenario 1 provides estimates of deaths without COVID-19. Scenario 2 considers that COVID-19 deaths accounted for 5.3\% of total deaths until 20th December 2020. Scenarios 3, 4, and 5 project the estimates assuming that COVID-19 attributable deaths would increases to 6,8 and $10 \%$ of total deaths respectively. Expected deaths due to COVID-19 were distributed in accordance with the age distribution of COVID-19 as of date. Estimates of YPLL and DALY were made as follows.

\section{Years of potential life lost (YPLL)}

YPLL is a summary measure of premature mortality that estimates the average years a person would have lived had he or she not died prematurely [28]. YPLL is estimated as:

$$
Y P L L=\sum_{i=0}^{\infty} d_{i} * L_{i}
$$

Where $L_{i}$ represents the life expectancy at age $i$ and $d_{i}$ represents the number of deaths at age $i$. It is a selfweighted estimate, which gives a higher weight to the deaths occurring at younger ages and a lower weight to the deaths at higher ages [28, 29]. The deaths at each age are weighted by age-specific life expectancy.

\section{Disability adjusted life years (DALY)}

DALY is a summary measure of health of a population, combining mortality and non-fatal health outcomes. DALY is commonly used to measure the difference between a current situation of health and an ideal situation, where everyone lives up to the age of the standard life expectancy and in a perfect health [30]. It is estimated by summing the potential life lost due to premature mortality and productive years of life lost due to disability/disease [30]. It is calculated as:

$$
D A L Y=Y L L+Y L D
$$

Where YLL denotes the years of life lost due to premature mortality, and $Y L D$ denotes the years lived with disability.

YLL and YLD were calculated considering the discounting rate of $3 \%$. Discounting rate shows the social preference of a healthy year now, rather than in the future. The value of a year of life is generally decreased annually by a fixed percentage. The World Bank Disease Control Priorities study and the Global Burden of Disease (GBD) project both used a 3\% discount rate, and the US Panel on Cost-Effectiveness in Health and Medicine recently recommended that the economic analyses of health also use a $3 \%$ real discount rate to adjust both costs and health outcomes [31, 32].

YLL is estimated as:

$$
Y L L=\frac{N}{r}\left(1-e^{-r L}\right)
$$

Where $N$ is the number of deaths, $L$ is the life expectancy at the age of death, and $r$ is the discount rate.

$$
Y L D=\frac{\left(I * D W * L *\left(1-e^{-r L}\right)\right)}{r}
$$

Where $I$ is the number of incidence/prevalence cases, $D W$ is a disability weight (a weight factor that reflects the severity of the disease on a scale from 0 (equivalent to perfect health) to 1 (equivalent to being dead)), and $L$ is the duration of the disability.

As COVID-19 is a novel disease, its disability weight is not available. Since it is a severely infectious disease having an acute period and is associated with the lower respiratory tract infection [33]. Hence, we have used the disability weight of 0.133 , as a proxy of COVID-19 (available elsewhere [34]. The duration of disability of 60 days was used because the patients of COVID-19 have been hospitalized for an average of 30 days, and after discharge, are quarantined for 14-28 days approximately [35, 36].

\section{Result}

Table 1 provides the key indicators of the COVID-19 infection and the associated mortality for Maharashtra and India. Since the onset of the pandemic, COVID-19 has infected more than 1.8 million people, of whom 48,746 had died in Maharashtra until 20th December 2020. COVID-19 attributable deaths amount to $5.3 \%$ of the total deaths. These additional deaths could have been prevented in the absence of COVID-19. The case-fatality 
Table 1 Summary indicators of population and COVID-19 indicators in Maharashtra and India 2020

\begin{tabular}{lll}
\hline Summary Indicators & Maharashtra & India \\
\hline Total Population in 000 S (2020) & 123,961 & $1,355,417$ \\
Estimated number of deaths without COVID-19 & 872,081 & $12,548,843$ \\
Number of deaths with COVID19 (until 20th December 2020) & 48,746 & 920,827 \\
Total deaths including deaths due to COVID-19 & 5.3 & 145,845 \\
COVID-19 deaths as a share of total deaths until 20th December 2020 & 2.57 & $12,694,688$ \\
Case-fatality ratio & $1,896,518$ & 1.15 \\
Total number of COVID-19 infection until 20th December 2020 & 15.3 & 1.45 \\
Infection rate (per thousand population) until 20th December 2020 & 73.2 & $10,056,281$ \\
Life expectancy pre-COVID-19 & 0.8 & 7.4 \\
Reduction in life expectancy with COVID-19 deaths accounting to 5.3\% & 69.7 \\
\hline
\end{tabular}

ratio in the state is 2.57 , higher than the national average of 1.5. The rate of infection in Maharashtra (15 infected per 1000 people) is more than double compared to the national average (7 infected per 1000 people). In 2018 (the pre-COVID-19 period), the life expectancy at birth was 73.2 years in the state compared to 69.7 years in India as a whole.

Appendix 1 presents the number of confirmed cases and COVID-19 attributable deaths by age group in Maharashtra until 20th December 2020. Figure 1 estimates the age-specific case fatality ratio in the state. The ASCFR shows an increasing pattern with age. It is as low as 0.14 in the age group 10 -year and reaches $7 \%$ by age 60 and $11 \%$ in the age group 80 years and above.

Figure 2 compares the life table probability of deaths with and without the COVID-19 infection in Maharashtra. Age-specific probability of deaths was estimated by assuming that the age pattern of mortality without COVID-19 would have remained the same as during the period 2014-2018. The gap between the two curves shows the difference in probability of death with and without the COVID-19 pandemic. It is observed that the infection has affected the age pattern of mortality. This pattern suggests that after the age of 44 , the probability of dying with COVID-19 is increases with age compared to the probability of dying without COVID-19. The probability of death till the age of 44 is similar both preand during the COVID-19 pandemic. The probability of dying with COVID-19, compared to without COVID-19, is higher among those aged 45-75 with COVOD-19 compare to without COVID-19.

Figure $3 \mathrm{a}$ and $\mathrm{b}$ depict the premature mortality by age $70\left({ }_{70} q_{0}\right)$ and in the prime working-age group of 20-64 $\left({ }_{44} q_{20}\right)$ in pre- and during the COVID-19 pandemic. The premature mortality pre-COVID-19 was 0.34 but increased to 0.36 with COVID-19. Given the current mortality pattern, if the share of deaths attributable to the infection reaches 8 and $10 \%$, the premature mortality $\left({ }_{70} q_{0}\right)$ would increase to 0.37 and 0.38 , respectively. In the working-age group $\left({ }_{44} q_{20}\right)$, the probability of death due to the current rate of infection has increased to 0.16 from 0.15 in the pre-COVID-19 period. Under the assumed 10\% COVID-19 attributable death share scenario, the probability of death in the working-age group would increase to 0.17 .

Table 2 presents the estimates of life expectancy by age group without COVID-19 and with varying degrees

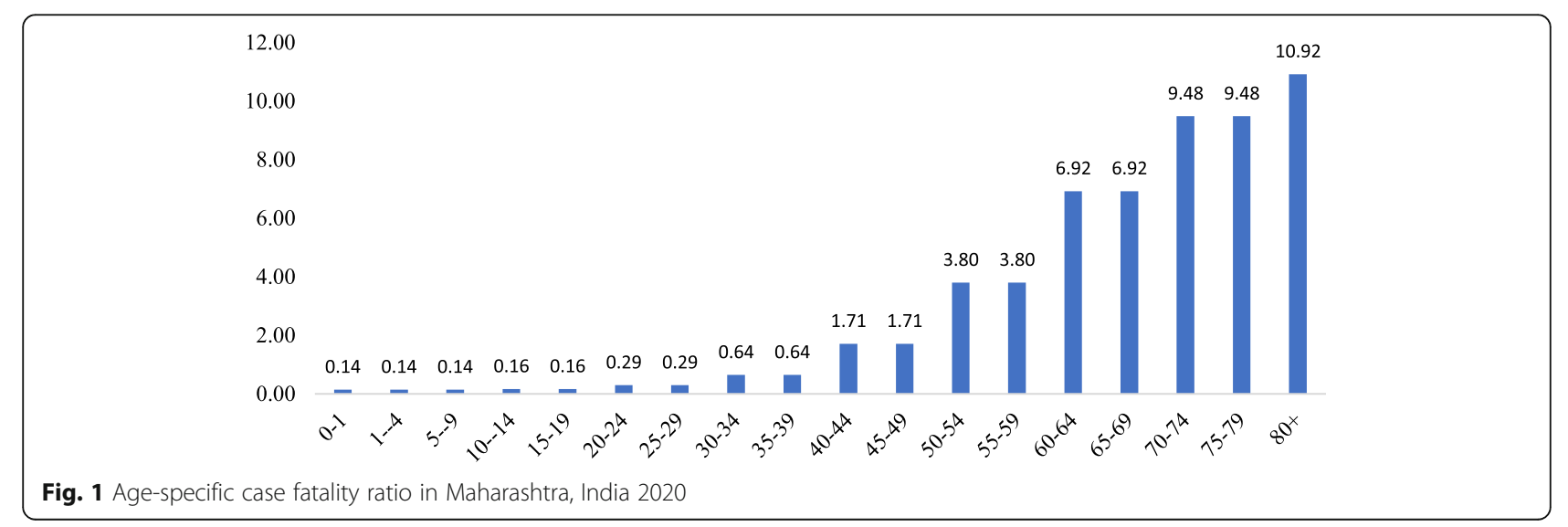



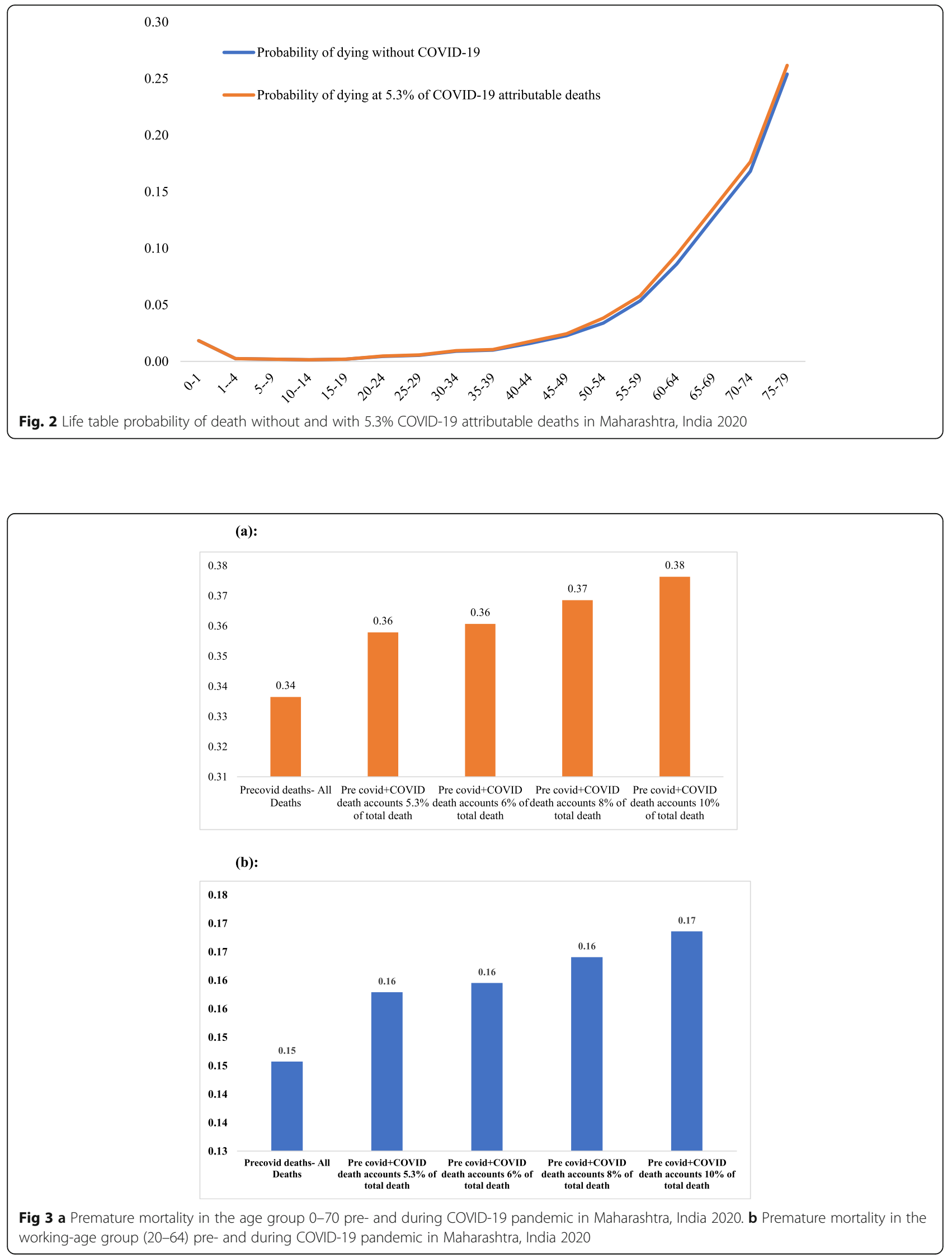
Table 2 Life expectancy under various scenarios of COVID-19 attributable mortality in Maharashtra, India 2020

\begin{tabular}{|c|c|c|c|c|c|c|}
\hline $\begin{array}{l}\text { Age } \\
\text { group }\end{array}$ & $\begin{array}{l}\text { Life } \\
\text { expectancy } \\
\text { without } \\
\text { COVID-19 }\end{array}$ & $\begin{array}{l}\text { Life expectancy } \\
\text { with COVID-19 } \\
\text { deaths of } 5.3 \%\end{array}$ & $\begin{array}{l}\text { Life expectancy } \\
\text { with COVID-19 } \\
\text { deaths of } 6 \%\end{array}$ & $\begin{array}{l}\text { Life expectancy } \\
\text { with COVID-19 } \\
\text { deaths of } 8 \%\end{array}$ & $\begin{array}{l}\text { Life expectancy } \\
\text { with COVID-19 } \\
\text { deaths of } 10 \%\end{array}$ & $\begin{array}{l}\text { Reduction in life expectancy } \\
\text { (pre COVID-19 to } 5.3 \% \text { COVID-19 } \\
\text { attributable deaths) }\end{array}$ \\
\hline$\overline{0-1}$ & 73.2 & 72.4 & 72.3 & 72.1 & 71.8 & 0.8 \\
\hline $1-4$ & 73.5 & 72.8 & 72.7 & 72.4 & 72.1 & 0.8 \\
\hline $5-9$ & 69.7 & 69.0 & 68.9 & 68.6 & 68.3 & 0.8 \\
\hline $10-14$ & 64.9 & 64.1 & 64.0 & 63.7 & 63.4 & 0.8 \\
\hline 15-19 & 59.9 & 59.2 & 59.1 & 58.8 & 58.5 & 0.8 \\
\hline $20-24$ & 55.1 & 54.3 & 54.2 & 53.9 & 53.6 & 0.8 \\
\hline $25-29$ & 50.3 & 49.5 & 49.4 & 49.2 & 48.9 & 0.8 \\
\hline $30-34$ & 45.6 & 44.8 & 44.7 & 44.4 & 44.2 & 0.8 \\
\hline $35-39$ & 41.0 & 40.2 & 40.1 & 39.9 & 39.6 & 0.7 \\
\hline $40-44$ & 36.3 & 35.6 & 35.5 & 35.3 & 35.0 & 0.7 \\
\hline $45-49$ & 31.9 & 31.2 & 31.1 & 30.9 & 30.6 & 0.7 \\
\hline $50-54$ & 27.6 & 26.9 & 26.9 & 26.6 & 26.4 & 0.6 \\
\hline $55-59$ & 23.4 & 22.9 & 22.8 & 22.6 & 22.4 & 0.5 \\
\hline $60-64$ & 19.6 & 19.2 & 19.1 & 18.9 & 18.8 & 0.5 \\
\hline $65-69$ & 16.2 & 15.9 & 15.9 & 15.7 & 15.6 & 0.3 \\
\hline $70-74$ & 13.3 & 13.0 & 13.0 & 12.9 & 12.8 & 0.3 \\
\hline $75-79$ & 10.4 & 10.2 & 10.2 & 10.2 & 10.1 & 0.2 \\
\hline $80+$ & 8.1 & 8.0 & 8.0 & 7.9 & 7.9 & 0.1 \\
\hline
\end{tabular}

of COVID-19 attributable deaths in Maharashtra. Life expectancy in each age group with and without the COVID-19 infection exhibits the changing age-specific survival pattern. It can be observed that life expectancy has reduced in each scenario of the COVID-19 infection. In the pre-COVID-19 period, life expectancy at birth (age 0) was 73.2 years, which with the current infection, has reduced to 72.4 years. Therefore, life expectancy has reduced by 0.8 years in the state, A disproportionate reduction of life expectancy was observed across age. With an increase in the share of COVID-19 attributable deaths to $10 \%$, life expectancy would reduce to 71.8 years in the state.

Figure 4 shows the reduction in life expectancy at birth in various scenarios of COVID-19 attributable deaths in Maharashtra. Estimates suggest that the ongoing COVID-19 pandemic has significantly affected the life expectancy in the state. Life expectancy has already shrunk by 0.8 years due to the current level of COVID19 attributable deaths. in the scenario that COVID-19 attributable deaths would amount to 6,8 , and $10 \%$ of total deaths in the state, the life expectancy at birth would reduce by $0.9,1.1$, and 1.4 years respectively.

Table 3 presents the estimates of years of potential life lost (YPLL) without COVID-19 and with various level of deaths attributable to COVID-19 by age group in
Maharashtra. YPLL was estimated at 17.4 million in the absence of infection. COVID-19 added more than 1.06 million YPLL loss in the state. It can be observed that the age composition of YPLL with infection is substantially different without infection. COVID-19 has significantly affected the working adults aged 45-65 years with their percentage share of YPLL increased to $50 \%$ compare to $33 \%$ without infection. In contrast, the percentage share of YPLL among infants ( $0-1$ years of age) has decreased to $0.03 \%$ with COVID-19 compare to $6.5 \%$ without it. In the scenario that COVID-19 attributable deaths increase to 6,8 and 10\%, YPLL would increase by 1.2 million, 1.5 million and 1.9 million respectively.

Table 4 shows the estimated age-specific DALY in various scenarios of COVID-19 attributable mortality in Maharashtra. With the current share of deaths attributable to the infection, we estimated DALYs for all ages to be 6.1 per thousand population. DALY would change in each scenario of COVID-19 attributable deaths. If COVID-19 accounts for a $6 \%$ death share, DALYs would increase to 7 per thousand population. With an increase in the share of deaths attributable to COViD-19 to 8 and $10 \%$, DALYs would increase to 9.2 and 11.5 per thousand population respectively. The age pattern of DALY suggests that the age group 60-64 makes the highest contribution to the overall DALY. 


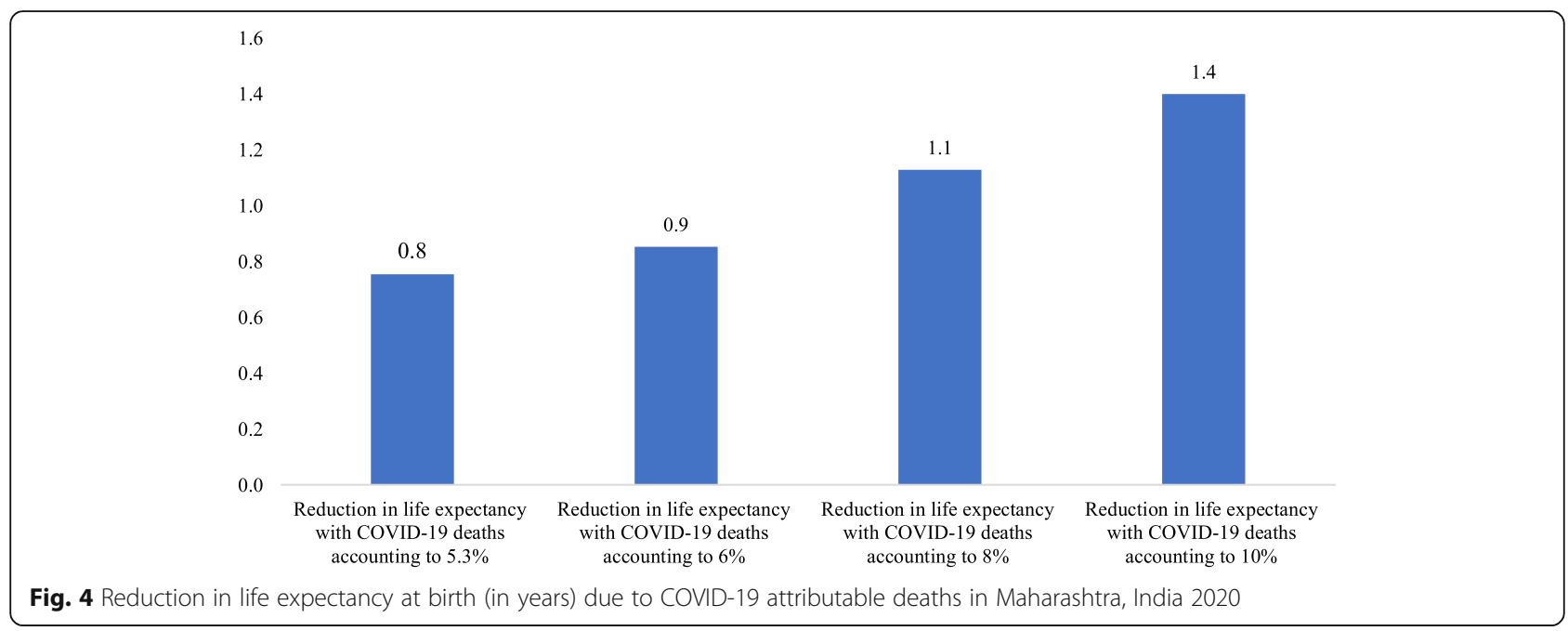

Table 3 Estimates of years of potential life lost (YPLL) in various scenarios of COVID-19 attributable deaths in Maharashtra, India 2020

\begin{tabular}{|c|c|c|c|c|c|c|c|c|c|c|}
\hline \multirow[t]{2}{*}{ Age group } & \multicolumn{2}{|c|}{ Without COVID-19 } & \multicolumn{2}{|c|}{$\begin{array}{l}\text { At } 5.3 \% \text { deaths } \\
\text { attributable to COVID- } \\
19\end{array}$} & \multicolumn{2}{|c|}{$\begin{array}{l}\text { At } 6 \% \text { deaths } \\
\text { attributable to COVID- } \\
19\end{array}$} & \multicolumn{2}{|c|}{$\begin{array}{l}\text { At } 8 \% \text { deaths } \\
\text { attributable to COVID- } \\
19\end{array}$} & \multicolumn{2}{|c|}{$\begin{array}{l}\text { At } 10 \% \text { deaths } \\
\text { attributable to COVID- } \\
19\end{array}$} \\
\hline & YPLL & $\begin{array}{l}\text { Share of } \\
\text { YPLL }\end{array}$ & YPLL & $\begin{array}{l}\text { Share of } \\
\text { YPLL }\end{array}$ & YPLL & $\begin{array}{l}\text { Share of } \\
\text { YPLL }\end{array}$ & YPLL & $\begin{array}{l}\text { Share of } \\
\text { YPLL }\end{array}$ & YPLL & $\begin{array}{l}\text { Share of } \\
\text { YPLL }\end{array}$ \\
\hline $0-1$ & $1,141,269$ & 6.56 & 335 & 0.03 & 379 & 0.03 & 503 & 0.03 & 627 & 0.03 \\
\hline $1-4$ & 334,770 & 1.92 & 3028 & 0.28 & 3427 & 0.29 & 4552 & 0.29 & 5669 & 0.29 \\
\hline $5-9$ & 245,442 & 1.41 & 3328 & 0.31 & 3767 & 0.31 & 5002 & 0.31 & 6227 & 0.32 \\
\hline $10-14$ & 185,706 & 1.07 & 6445 & 0.61 & 7294 & 0.61 & 9683 & 0.61 & 12,051 & 0.61 \\
\hline $15-19$ & 243,737 & 1.40 & 6339 & 0.60 & 7173 & 0.60 & 9518 & 0.60 & 11,842 & 0.60 \\
\hline $20-24$ & 546,719 & 3.14 & 25,006 & 2.35 & 28,292 & 2.35 & 37,528 & 2.36 & 46,671 & 2.37 \\
\hline $25-29$ & 617,269 & 3.55 & 23,073 & 2.17 & 26,100 & 2.17 & 34,605 & 2.18 & 43,017 & 2.18 \\
\hline $30-34$ & 894,629 & 5.14 & 60,284 & 5.67 & 68,180 & 5.67 & 90,350 & 5.68 & 112,252 & 5.69 \\
\hline $35-39$ & 822,372 & 4.73 & 49,804 & 4.68 & 56,317 & 4.69 & 74,590 & 4.69 & 92,622 & 4.70 \\
\hline $40-44$ & $1,037,829$ & 5.96 & 110,039 & 10.35 & 124,399 & 10.35 & 164,647 & 10.35 & 204,310 & 10.36 \\
\hline $45-49$ & $1,163,562$ & 6.69 & 85,711 & 8.06 & 96,879 & 8.06 & 128,160 & 8.06 & 158,954 & 8.06 \\
\hline $50-54$ & $1,320,430$ & 7.59 & 172,733 & 16.25 & 195,187 & 16.24 & 258,010 & 16.23 & 319,757 & 16.21 \\
\hline $55-59$ & $1,470,710$ & 8.45 & 120,684 & 11.35 & 136,372 & 11.35 & 180,265 & 11.34 & 223,405 & 11.33 \\
\hline $60-64$ & $1,576,967$ & 9.06 & 155,767 & 14.65 & 175,994 & 14.64 & 232,553 & 14.62 & 288,100 & 14.61 \\
\hline $65-69$ & $1,533,804$ & 8.81 & 100,527 & 9.45 & 113,620 & 9.45 & 150,284 & 9.45 & 186,362 & 9.45 \\
\hline $70-74$ & $13,263,76$ & 7.62 & 71,380 & 6.71 & 80,700 & 6.71 & 106,823 & 6.72 & 132,571 & 6.72 \\
\hline 75-79 & $1,203,351$ & 6.92 & 40,928 & 3.85 & 46,286 & 3.85 & 61,321 & 3.86 & 76,165 & 3.86 \\
\hline $80+$ & $1,735,454$ & 9.97 & 27,831 & 2.62 & 31,478 & 2.62 & 41,718 & 2.62 & 51,836 & 2.63 \\
\hline Total & $\begin{array}{l}17,400 \\
395\end{array}$ & 100.0 & $\begin{array}{l}1,063 \\
242\end{array}$ & 100.0 & $\begin{array}{l}1,201 \\
843\end{array}$ & 100.0 & $\begin{array}{l}1,590 \\
112\end{array}$ & 100.00 & $\begin{array}{l}1,972 \\
438\end{array}$ & 100.00 \\
\hline $0-44$ & $6,069,743$ & 34.88 & 2876,80 & 27.06 & 325,328 & 27.07 & 430,979 & 27.10 & 535,288 & 27.14 \\
\hline $45-64$ & $5,531,668$ & 31.79 & 534,895 & 50.31 & 604,432 & 50.29 & 798,988 & 50.25 & 990,216 & 50.20 \\
\hline $65+$ & $5,798,985$ & 33.33 & 240,667 & 22.64 & 272,083 & 22.64 & 360,145 & 22.65 & 446,934 & 22.66 \\
\hline $\begin{array}{l}\text { Rate of } \\
\text { YPLL }\end{array}$ & 140.37 & & 8.58 & & 9.70 & & 12.83 & & 15.91 & \\
\hline
\end{tabular}




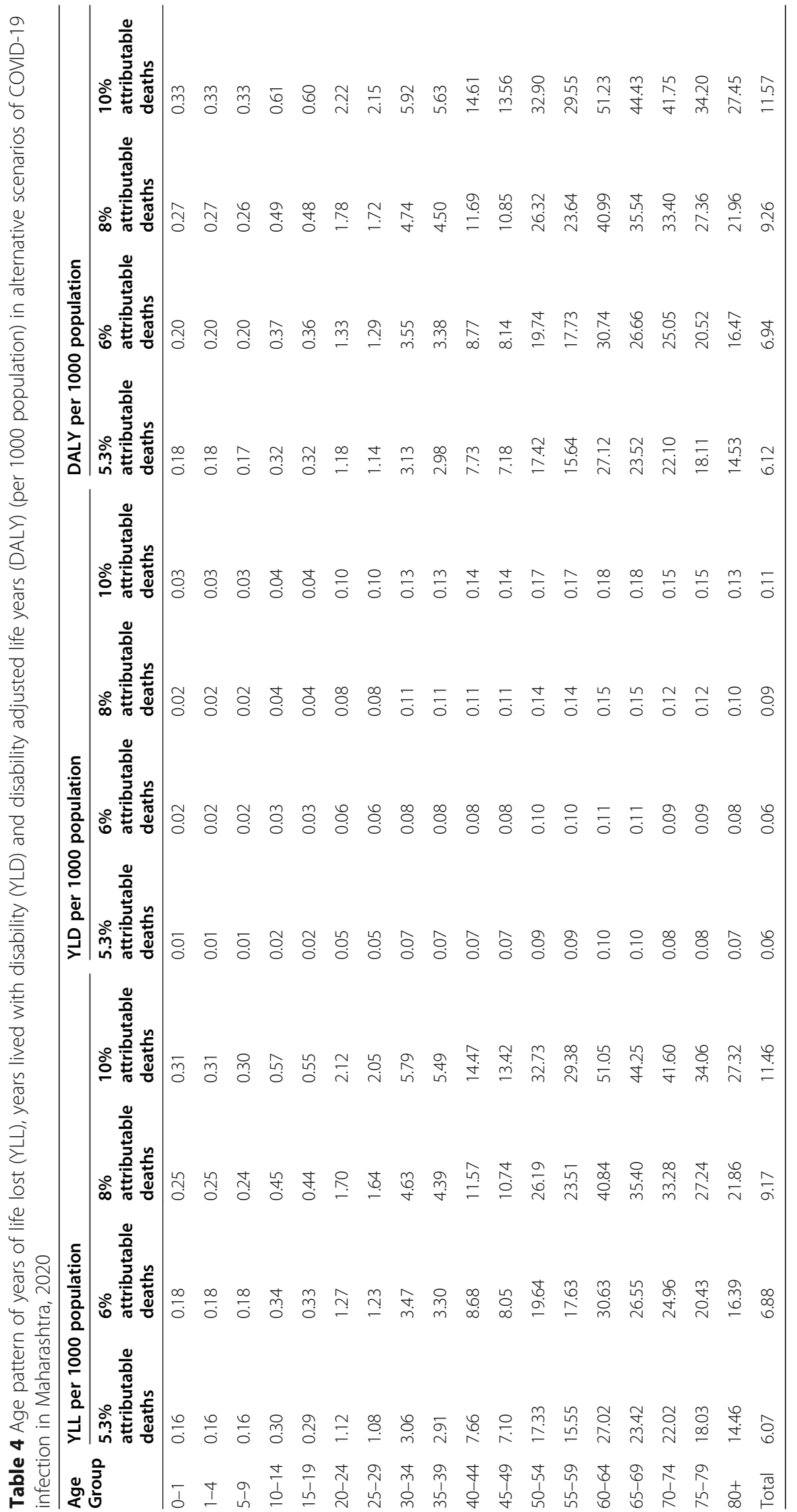




\section{Discussion and conclusion}

In a short period of 1 year, the COVID-19 pandemic has emerged as the largest-ever health crisis globally, nationally, and locally. Despite several measures to contain the spread of the virus, the infection has intensified the disease burden, increased premature mortality, increased short- and long-term morbidity, raised health care costs, reduced income, increased unemployment, and above all, generated a psychological scare worldwide. The second and the third waves of COVID-19 infection are underway in many of the worst-affected countries. The geographical spread of the COVID-19 infection and the associated mortality has largely been uneven. Its impact varies across and within the countries. India is the second-worst affected country with respect to the number of COVID-19 infections, where the disease remains a constant threat due to the large population, densely populated cities, slums, compromised hygiene practices, inadequate health care facilities, and the lack of other development indicators. The COVID-19 infection rate and fatalities are quite uneven across India, with Maharashtra being the worst affected state, accounting for one-third of the total COVID-19 attributable deaths. In this context, this is the first-ever study to examine the impact of COVID-19 on life expectancy, premature mortality, and disability-adjusted life years in Maharashtra, India. The following are the salient findings.

First, the COVID-19 infection accounted for 5.3\% of all causes of death in the state until 20th December 2020. The crude death rate has increased from 7 per thousand in the pre-COVID-19 period to 7.4 per thousand population during COVID-19, which is not a minor shift. A similar finding has been reported in a study from USA [37]. Second, the COVID-19 epidemic has significantly raised the likelihood of dying in the age group 45-70, comprising a large majority of the working adult population. At the current infection rate, the share of premature mortality among working adults (20-64) is 16 , and $36 \%$ before age 70 . In a hypothetical scenario where the level of COVID-19 attributable deaths increase to $10 \%$, the probability of dying prematurely in the age group (0-70) and in the working-age group of 20-64 would rise to 38 and $18 \%$ respectively. Similar findings have been reported by various studies across the globe $[38,39]$. These observations on the mortality front conveys not only the survival adversity brought about by COVID-19, but also composition of the adversity, which is rather alarming and has long-term implications. Apart from the reversal in the trend of the crude death rate (CDR), the increase in the premature mortality among working adults has resulted in a loss of productivity and put a share of households in distress with the loss of the bread earner. This may lead to a range of adversities like discontinuation of education by children and debt burden among distressed households with gendered derivatives, wherein dependent girls, children, and women will become worse off. Premature mortality, unless otherwise sufficiently protected with insurance and economic protection can have a devastating impact on individual households, which may not be apparent in the macro scene. Third, with the current share of COVID-19 induced mortality, life expectancy has already shrunk by 0.8 years in the state. If the virus continues to spread and mortality reaches $10 \%$, loss in life expectancy is likely to be 1.4 years. Our findings are consistent with literature $[4,8,18]$. A high reduction of life expectancy (2.94 years) has been observed in USA [40]. Fourth, The COVID-19 attributable deaths have caused about 1.06 million YPLL in the state. The majority of the loss in YPLL has been among the working adults aged 4564 years. This disproportionately high share of personyears life lost in the ages 45-64 has undoubtedly increase the dependency burden at the household level, which calls for micro-monitoring of such households and adoption of appropriate protective measures for the dependents of the adult victims. Lastly, the COVID-19 induced mortality has substantial implications for DALY as well. At the current share of COVID-19 induced mortality, the loss of DALY was estimated at 6.1 per thousand population. With an increase in the deaths share to 8 and $10 \%$ of mortality, DALY loss is estimated to increase to 9.2 and 11.5 per thousand population, respectively.

The new strains of COVID-19 at various places across the globe have alarmed the world about the higher transmission probability and higher associated mortality than the existing strains of virus [41]. Therefore, advanced preparedness needs to be in place to tackle the rapid spread of the infection until a substantial share of the population is vaccinated. Since the beginning of the pandemic, the national and states governments in India have made several efforts to contain the spread of the virus with measures like imposing a complete lockdown, promoting hygiene and hand wash practices, executing a phase-wise unlocking, promoting social distancing norms and mask wearing, identifying hot spots, and others. Though the infection rate had slowed down in the country, COVID-19 infection is surging again, whereas Maharashtra continues to be the worst affected state in the country. In recent months, Maharashtra has accounted for about half of the new COVID-19 infections in the country. The likely reasons behind this is the densely populated cities, the presence of a large number of slums, the large inflow and outflow of migrants, the engagement of a substantial labour force in the unorganized sector, along with a number of demographic challenges. The potential for rapid transmission and the implied fatalities may well reverse the survival scene in the state as indicated by this study [12].

It is heartening to note that India has been successful in developing two of the vaccines, namely 'Covaxin' and 
'Covishield', and started the vaccination exercise on 16th January 2021. As of 5th March 2021, more than 15 million people have been vaccinated in the country of whom 1.4 million are in the state of Maharashtra [22]. The current vaccination program is limited to health care workers, senior citizens and persons with comorbidities. Giving the fact that half of the newly infected cases are from Maharashtra, it is suggested that the state be given priority in vaccination. The vaccines are being supplied by the central government while the vaccinated are being carried out by the state governments. The state of Maharashtra and the cities in the state should be accorded a high priority in the vaccination program. Also the IEC (Information Education and Communication) on the efficacy of the vaccination should be intensified to reduce the vaccine hesitancy and to eliminate the mistrust among some sections of the population.

Given that the risk of The COVID-19 infection is age conditioned, with the vulnerability being greater among those aged 40 and above, and that the virulence of the disease intensifies with multimorbid conditions and a compromised immunity, the rate of infection has been quite high in the later ages, with an increased risk of fatality as well. In view of the need for out-of-home activities for livelihood and the prevalence of inappropriate working conditions that hardly allow for COVID protocols of SMS (Sanitary Practice, Masking and Safe Social Distance) to be followed, there needs to be a greater focus on this vulnerable population to attain a balance between work and life.

In conclusion, this exercise makes a precise assessment of the survival scenario keeping in mind the continuation of the COVID-19 pandemic. The study emphasize the need for robust protection measures to mitigate the consequences of the disease on victim households and for prioritizing the vaccination program in the state of Maharashtra. The very specific vulnerability to this infection calls for suitable action on a variety of fronts like work environments out of home, means of communication in keeping with the COVID-19 protocols, and adequate sanitary and hygiene amenities in the living environment to restrict the spread of the infection and to bring it under control before prior to the vaccination drive goes into in full swing.

\section{Supplementary Information}

The online version contains supplementary material available at https://doi. org/10.1186/s12879-021-06026-6.

Additional file 1: Appendix 1. Age-specific COVID-19 confirmed cases, deaths and estimated case fatality ratio (CFR) in Maharashtra, 20th December, 2020. Appendix 2. Estimated deaths without COVID-19 and with varying level of COVID-19 attributable deaths in Maharashtra, India, 20th December, 2020.
Acknowledgments

Not applicable.

Authors' contributions

Conceptualization and design of study: SKM and GV; analysis and interpretation of data: GV; drafting the manuscript: GV and SKM; critical revision of the manuscript for important intellectual content: GV, SKM, USM, MD and US. The authors read and approved the final manuscript.

\section{Funding}

Not applicable.

\section{Availability of data and materials}

Multiple data sources were used in the current study. The data is available in the public domain and is accessible online at:

https://api.covid19india.org/, https://nhm.gov.in/New_Updates_2018/Report_ Population_Projection_2019.pdf, https://censusindia.gov.in/vital_statistics/ Appendix_SRS_Based_Life_Table.html,

https://timesofindia.indiatimes.com/city/mumbai/one-in-3-covid-deathsacross-maharashtra-was-of-person-in-61-70-age-group/articleshow/79599564. cms, https://timesofindia.indiatimes.com/city/mumbai/maharashtra-mumbaisee-slight-drop-in-cases-marginal-rise-in-deaths/articleshow/79831787.cms

\section{Declarations}

Ethics approval and consent to participate

Not applicable.

\section{Consent for publication \\ Not Applicable.}

\section{Competing interests}

The authors declare that they do not have any competing interest.

\section{Author details}

${ }^{1}$ International Institute for Population Sciences, Govandi Station Road, Deonar, Mumbai, Maharashtra 400088, India. ${ }^{2}$ Department of Fertility Studies, International Institute for Population Sciences, Mumbai, India. ${ }^{3}$ Centre for Development Studies, Prashant Nagar, Medical College P.O, Ullor

Thiruvananthapuram, Kerala, India. ${ }^{4}$ Centre for Chronic Disease Control, New Delhi, India.

Received: 3 January 2021 Accepted: 30 March 2021

Published online: 12 April 2021

\section{References}

1. Worldometer. Coronavirus Update (Live): Cases and Deaths from COVID-19 Virus Pandemic [Internet]. Worldometers. 2020. p. 1. Available from: https:// www.worldometers.info/coronavirus/.

2. UN Department of Economics and Social Affairs. World Population Prospects - Population Division - United Nations [Internet]. Int J Logistics Manage. 2019;9:1-13 [cited 2021 Jan 2]. Available from: https://esa.un.org/ unpd/wpp/.

3. Wang D, Hu B, Hu C, Zhu F, Liu X, Zhang J, et al. Clinical characteristics of 138 hospitalized patients with 2019 novel coronavirus-infected pneumonia in Wuhan, China. JAMA. 2020;323(11):1061-9. https://doi.org/10.1001/jama.2 020.1585 .

4. Marois G, Muttarak R, Scherbov S. Assessing the potential impact of COVID19 on life expectancy. PLoS One. 2020;15(9 September):1-12 Available from: https://doi.org/10.1371/journal.pone.0238678.

5. Chang D, Lin M, Wei L, Xie L, Zhu G, Cruz CS, Sharma L. Epidemiologic and clinical characteristics of novel coronavirus infections involving 13 patients outside Wuhan, China. Jama. 2020;323(11):1092-3. https://doi.org/10.1001/ja ma.2020.1623.

6. Onder G, Rezza G, Brusaferro S. Case-fatality rate and characteristics of patients dying in relation to COVID-19 in Italy. JAMA. 2020;323(18):1775-6.

7. Russell TW, Hellewell J, Jarvis Cl, Van Zandvoort K, Abbott S, Ratnayake R, Flasche S, Eggo RM, Edmunds WJ, Kucharski AJ, CMMID COVID-19 working group. Estimating the infection and case fatality ratio for coronavirus disease (COVID-19) using age-adjusted data from the outbreak on the Diamond Princess cruise ship, February 2020. Eurosurveillance. 2020;25(12): 
2000256. Available from: https://doi.org/10.2807/1560-7917.ES.2020.25.12.2 000256.

8. Trias-Llimos S, Riffe T, Bilal U. Monitoring life expectancy levels during the COVID-19 pandemic: Example of the unequal impact of the first wave on Spanish regions. PLoS One. 2020;15(11 November):1-10.

9. Mohanty SK, Sahoo U, Mishra USDM. Age Pattern of Premature Mortality under varying scenarios of COVID-19 Infection in India. medRxiv. 2020;(1 January) Available from: https://www.medrxiv.org/content/10.1101/2020. 06.11.20128587v1.

10. Leung C. Risk factors for predicting mortality in elderly patients with COVID19: a review of clinical data in China. Mech Ageing Dev. 2020;188(April): 111255 Available from: https://doi.org/10.1016/j.mad.2020.111255.

11. Docherty AB, Harrison EM, Green CA, Hardwick HE, Pius R, Norman L, Holden KA, Read JM, Dondelinger F, Carson G, Merson L. Features of 20133 UK patients in hospital with covid-19 using the ISARIC WHO Clinical Characterisation Protocol: prospective observational cohort study. bmj. 2020; 369. https://doi.org/10.1136/bmj.m1985.

12. Lai CC, Wang CY, Wang YH, Hsueh SC, Ko WC, Hsueh PR. Global epidemiology of coronavirus disease 2019 (COVID-19): disease incidence, daily cumulative index, mortality, and their association with country healthcare resources and economic status. Int J Antimicrob Agents. 2020;55(4):105946 Available from: https://doi.org/10.1016/j.ijantimicag.2020.105946.

13. Ji Y, Ma Z, Peppelenbosch MP, Pan Q. Potential association between COVID19 mortality and health-care resource availability. Lancet Glob Heal. 2020; 8(4):e480 Available from: https://doi.org/10.1016/S2214-109X(20)30068-1.

14. Zhou F, Yu T, Du R, Fan G, Liu Y, Liu Z, et al. Clinical course and risk factors for mortality of adult inpatients with COVID-19 in Wuhan, China: a retrospective cohort study. Lancet. 2020;395(10229):1054-62 Available from: https://doi.org/10.1016/S0140-6736(20)30566-3.

15. Verity R, Okell LC, Dorigatti I, Winskill P, Whittaker C, Imai N, et al. Estimates of the severity of coronavirus disease 2019: a model-based analysis. Lancet Infect Dis. 2020;20(6):669-77. https://doi.org/10.1016/\$1473-3099(20)30243-7.

16. Carfi A, Bernabei R, Landi F. Persistent symptoms in patients after acute COVID-19. Jama. 2020;324(6):603-5. https://doi.org/10.1001/jama.2020.12603.

17. Ghislandi S, Muttarak R, Sauerberg M, Scotti B. News from the front: Estimation of excess mortality and life expectancy in the major epicenters of the COVID-19 pandemic in Italy. medRxiv. 2020. Available from: https:// doi.org/10.1101/2020.04.29.20084335.

18. Mohanty SK, Dubey M, Mishra USSU. Impact of COVID-19 Attributable Deaths on Longevity, Premature Mortality and DALY: Estimates of USA, Italy, Sweden and Germany. medRxiv. 2020; Available from: https://www.medrxiv. org/content/10.1101/2020.07.06.20147009v1.

19. Bhagat RB, Reshmi RS, Sahoo H, Roy AK, Govil D. The COVID-19, migration and livelihood in India: challenges and policy issues. Migr Lett. 2020;17(5): 705-18.

20. Bodrud-Doza M, Shammi M, Bahlman L, Islam AR, Rahman M. Psychosocial and socio-economic crisis in Bangladesh due to COVID-19 pandemic: a perception-based assessment. Frontiers in public health. 2020;8:341. Available from: https://doi.org/10.3389/fpubh.2020.00341.

21. Sub-national HDI - Subnational HDI - Global Data Lab [Internet]. Available from: https://globaldatalab.org/shdi/shdi/IND/?levels=1\%2B4\&interpolation= 0\&extrapolation $=0 \&$ nearest_real=0\&years $=2018$.

22. COVID19-India API | api. A volunteer-driven, crowd-sourced database for COVID-19stats \& patient tracing in India (Online) [Internet]. 2020 [cited 2021 Jan 2]. Available from: https://api.covid19india.org/

23. Leung TYM, Chan AYL, Chan EW, Chan VKY, Chui CSL, Cowling BJ, et al. Short- and potential long-term adverse health outcomes of COVID-19: a rapid review. Emerg Microbes Infect. 2020;9(1):2190-9. https://doi.org/10.1 080/22221751.2020.1825914.

24. Ministry of Health and Family Welfare, (MoHFW). Population projections for India and states 2001-2026: Report of the techanical group on population projections [Internet]. New Delhi: Office of Registrar General and Census Commissioner, Government of India, New Delhi; 2006. Available from: https:// nhm.gov.in/New_Updates_2018/Report_Population_Projection_2019.pdf

25. Office of the Registrar General and Census Commissioner. SRS based Abridged Life table, 2014-18. New Delhi: Ministry of Home Affairs, Govt of India, New Delhi; 2019.

26. Times of India. One in 3 Covid deaths across Maharashtra was of person in 61-70 age group. 2020; Available from: https://timesofindia.indiatimes.com/ city/mumbai/one-in-3-covid-deaths-across-maharashtra-was-of-person-in-6170-age-group/articleshow/79599564.cms
27. Times of India. Maharashtra and Mumbai see slight drop in cases, marginal rise in deaths. 2020; Available from: https://timesofindia.indiatimes.com/city/ mumbai/maharashtra-mumbai-see-slight-drop-in-cases-marginal-rise-in-dea ths/articleshow/79831787.cms

28. Gardner JW, Sanborn JS. Years of potential life lost (YPLL) - what does it measure?. Epidemiology. 1990;1:322-9. Available from: http://www.jstor.org/ stable/25759821.

29. Werber D, Hille K, Frank C, Dehnert M, Altmann D, Müller-Nordhorn J, Koch J, Stark K. Years of potential life lost for six major enteric pathogens, Germany, 2004-2008. Epidemiol Infect. 2013;141(5):961-8. Available from: https://doi.org/10.1017/S0950268812001550.

30. World Health Organization. The Global Burden of Disease concept. Quantifying Environ Heal Impacts. 2002;27:40 Available from: https://www. who.int/quantifying_ehimpacts/publications/en/9241546204chap3.pdf.

31. WHO. WHO methods and data sources for the global burden of disease estimates 2000-2011 [Internet]. Geneva: World Health Organization; 2013. Available from: http://www.who.int/healthinfo/statistics/GlobalDA LYmethods_2000_2011.pdf?ua=1

32. Gold MR, Stevenson D, Fryback DG. HALYS and QALYS and DALYS, Oh My: similarities and differences in summary measures of population Health. Ann Rev Public Health. 2002;23(1):115-34. Available from: https://doi.org/10.114 6/annurev.publhealth.23.100901.140513.

33. Nurchis MC, Pascucci D, Sapienza M, Villani L, D'ambrosio F, Castrini F, et al. Impact of the burden of COVID-19 in Italy: results of disability-adjusted life years (dalys) and productivity loss. Int J Environ Res Public Health. 2020; 17(12):1-12.

34. Global Burden of Disease Study 2017 (GBD 2017) Disability Weights | GHDx [Internet]. [cited 2021 Mar 8]. Available from: http://ghdx.healthdata.org/ record/ihme-data/gbd-2017-disability-weights.

35. Jacobs LG, Gourna Paleoudis E, Lesky-Di Bari D, Nyirenda T, Friedman T, Gupta A, Rasouli L, Zetkulic M, Balani B, Ogedegbe C, Bawa H. Persistence of symptoms and quality of life at 35 days after hospitalization for COVID-19 infection. PloS one. 2020;15(12):e0243882. Available from: https://doi.org/1 0.1371/journal.pone.0243882

36. World Health Organization. Criteria for releasing COVID-19 patients from isolation. Sci Br. 2020;(17 June):1-5 Available from: https://www.who.int/ publications/i/item/criteria-for-releasing-covid-19-patients-from-isolation.

37. Stokes A, Lundberg DJ, Hempstead K, Elo IT, Preston SH. Assessing the impact of the covid-19 pandemic on US mortality: a county-level analysis. medRxiv. 2020. Available from: https://doi.org/10.1101/2020.08.31.20184036.

38. Ortiz-Prado E, Simbaña-Rivera K, Barreno LG, Diaz AM, Barreto A, Moyano C, et al. Epidemiological, socio-demographic and clinical features of the early phase of the COVID-19 epidemic in Ecuador. PLoS Negl Trop Dis. 2021;15(1): $1-18$.

39. Fielding-Miller R, Sundaram M, Brouwer K. Social determinants of COVID-19 mortality at the county level. PLoS One. 2020;15(10):1-11.

40. Goldstein JR, Lee RD. Erratum: Demographic perspectives on the mortality of COVID-19 and other epidemics (Proceedings of the National Academy of Sciences of the United States of America (2020) 117 (22035-22041) https:// doi.org/10.1073/pnas.2006392117). Proc Natl Acad Sci U S A. 2020;117(47): 29991.

41. About Variants of the Virus that Causes COVID-19 | CDC [Internet]. [cited 2021 Mar 10]. Available from: https://www.cdc.gov/coronavirus/2019-ncov/ transmission/variant.html.

\section{Publisher's Note}

Springer Nature remains neutral with regard to jurisdictional claims in published maps and institutional affiliations. 